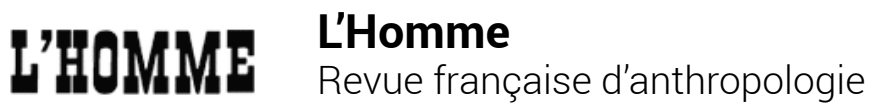

238 | 2021

Varia

\section{Valérie Robin Azevedo, Sur les sentiers de la violence. Politiques de la mémoire et conflit armé au Pérou}

\section{Sébastien Boulay}

\section{(2) OpenEdition}

1 Journals

Édition électronique

URL : https://journals.openedition.org/lhomme/40313

DOI : 10.4000//homme.40313

ISSN : 1953-8103

Éditeur

Éditions de l'EHESS

\section{Édition imprimée}

Date de publication : 19 août 2021

Pagination : 183-185

ISBN : 9782713228674

ISSN : 0439-4216

\section{Référence électronique}

Sébastien Boulay, «Valérie Robin Azevedo, Sur les sentiers de la violence. Politiques de la mémoire et conflit armé au Pérou », L'Homme [En ligne], 238 | 2021, mis en ligne le 19 août 2021, consulté le 13 septembre 2021. URL : http://journals.openedition.org//homme/40313; DOI : https://doi.org/10.4000/ Ihomme.40313 

aux non-spécialistes par un souci constant de contextualisation, s'accompagne d'une proposition méthodologique d'ethnographie des connexions globales, ainsi que d'une analyse qui engage la responsabilité éthique et théorique de l'ethnographe. En cela, Friction déborde du cadre des études portant sur la globalisation, sur les enjeux environnementaux ou sur l'Indonésie, dans lequel il s'inscrit néanmoins. La traduction élégante qu'en donnent Isabelle Stengers et Philippe Pignarre ${ }^{4}$ permet de mesurer, à quinze ans de distance, qu'il n'a rien perdu de son actualité ni de sa puissance. On peut toutefois regretter que l'autrice n'ait pu être sollicitée à l'occasion de cette traduction pour apporter quelques mises à jour à un livre qui garde encore l'empreinte des événements ayant marqué les États-Unis (et le reste du monde) au début des années 2000.

Théo Lebouc

4. Philippe Pignarre, qui dirige la collection des "Empêcheurs de penser en rond " dans laquelle cet ouvrage a été publié, était déjà à l'origine de la traduction, dans cette même collection, du troisième livre d'Anna Tsing, Le Champignon de la fin du monde. Sur la possibilité de vivre dans les ruines $d u$ capitalisme, paru en 2017 et dont Isabelle Stengers avait rédigé la préface.

Valérie Robin Azevedo Sur les sentiers de la violence. Politiques de la mémoire et conflit armé au Pérou Paris, Éd. de l'lHeAL, 2019, 267 p., bibl., ill., cartes («Travaux et mémoires » 9l).

$\mathrm{F}$ ONDÉ SUR des enquêtes de terrain menées dans les Andes rurales péruviennes, entre 2004 et 2012, cet ouvrage de Valérie Robin Azvedo porte sur les enjeux mémoriels contemporains de la guerre civile qui opposa, de 1980 à 1990, un groupe armé révolutionnaire maoïste, le Sentier lumineux, à l'État péruvien. Ce conflit meurtrier, qui aurait fait 70000 morts et 15000 disparus, s'est ensuite poursuivi dans l'espace public, «sur le terrain des mémoires». Si la préoccupation de l'autrice est bien de saisir le sens attribué aujourd'hui à ces violences de masse par les populations qui en ont été les victimes directes, elle met également en lumière les (en)jeux d'échelles au sein desquels ces mémoires concurrentes s'inscrivent, entre le local, le régional et le national, sachant que, pendant les premières années de la guérilla, la capitale, Lima, était peu informée de ce qui se déroulait dans le sud des Andes péruviennes. Le livre se compose de quatre chapitres: les deux premiers rappellent les éléments du contexte, fort utiles pour un lecteur non spécialiste de l'Amérique latine, avant d'aborder un examen critique de la production anthropologique sur ce conflit depuis trente ans, tandis que les deux derniers chapitres, consacrés à l'ethnographie de l'autrice dans le département d'Ayacucho, particulièrement touché par la guerre fraticide, exposent la manière dont s'élaborent les mémoires entre commémorations officielles, commémorations populaires et récits miraculeux.

C'est tout d'abord sur la spécificité de cette violence politique que Valérie Robin Azevedo nous invite à réfléchir, en revenant sur la naissance du Sentier lumineux et la personnalité de son fondateur, Abimael Guzmán, professeur de philosophie à l'Université d'Ayacucho et membre du parti communiste péruvien. Elle souligne notamment comment ce mouvement, entré en clandestinité au milieu des années 1970, n'hésitera pas à faire preuve d'une extrême violence à l'encontre des paysans andins pour les faire adhérer aux thèses maoïstes, tout en rejetant leur culture tenue pour archaïque et en imposant la langue espagnole aux quechuaphones. Le programme sentiériste de rééducation des masses, conçu avec l'appui de certains anthropologues, vise à éliminer une certaine lecture indigéniste 
de la paysannerie andine, jugée misérabiliste et essentialiste. L'intervention des forces gouvernementales en 1982-1983 entraîne massacres et disparitions dans les Andes, la stratégie de la guérilla sentiériste étant alors ouvertement de pousser l'armée à commettre des violences de masse, "d'induire au génocide» (p. 40). Arrivé au pouvoir en 1990, Alberto Fujimori met très rapidement en place un régime autoritaire qui conduira à un durcissement dans la militarisation du conflit, jusqu'à l'arrestation de Guzmán, en 1992, et la signature des accords de paix, en 1993 (p. 33). Ces victoires dans la lutte antisubversive permettent ensuite au régime de Fujimori de criminaliser toutes formes de dissidence et d'opposition, et d'instaurer l'amnistie des crimes commis par des forces gouvernementales en 1995 (p. 45). Après la démission de Fujimori en 2000, le gouvernement transitoire de Valentín Paniagua nomme une Commission de la vérité et de la réconciliation (CVR) chargée de faire la lumière sur les violences politiques et les atteintes aux droits de l'homme, de 2001 à 2003. Un Plan intégral de réparations est ensuite lancé en 2005, qui prévoit d'inscrire les futurs bénéficiaires sur un Registre unique des victimes (Ruv). L'autrice met très bien en évidence l'influence de ces instances sur la définition hautement politisée de la condition de victime et sur la hiérarchisation des morts du conflit, selon qu'ils aient été les victimes du Sentier lumineux ou bien celles de l'armée gouvernementale (p. 51).

Valérie Robin Azevedo montre ensuite de quelles manières le conflit a incité les anthropologues à revoir leurs approches des sociétés andines, n'hésitant pas à présenter ce conflit armé interne comme «un tournant capital pour l'anthropologie au Pérou» (p. 59). Elle propose ainsi une réflexion critique captivante sur le recours à l'andinité chez certains chercheurs des années 1960-1970, lesquels ont eu tendance à perpétuer «le stéréotype essentialiste d'un noyau culturel resté immuable dans le temps, insensible à tout changement et en marge de la société nationale, et ce en dépit des bouleversements politiques et socioéconomiques majeurs que traversait le Pérou dans son ensemble, dès les années $1960 »$ (p. 73). L'autrice revient sur la critique postmoderne de l'andinisme qui se fait jour dans les années 1990. Elle reconsidère également "les travers essentialistes de l'expertise anthropologique» du conflit (p. 91) et les positions des anthropologues dans l'analyse de ces violences de masse, dès les années 1980, sans oublier certaines conceptions racistes qui ont véhiculé toute une rhétorique sur la supposée "criminalité indigène». Puis, avec la mise en place de la Cvr au début des années 2000, elle décrit comment le champ mémoriel est devenu un champ majeur de l'anthropologie péruvienne, et comment les anthropologues sont parvenus à concilier leur implication dans cette instance, aux prises avec une "vision, souvent manichéenne, du discours "droitde-l'hommiste" sur les acteurs du conflit catalogués soit comme victimes innocentes soit comme assassins sans salut» (p. 117), avec une recherche exigeante sur les questions de mémoire. Dans ce chapitre consacré à l'épistémologie du conflit, on aurait souhaité que l'autrice se livre davantage, dans une démarche réflexive, sur son propre parcours et son positionnement au sein de ces débats éthiques et méthodologiques.

Après cette mise en perspective du rôle de l'anthropologie et des anthropologues dans l'analyse de l'implantation du mouvement sentiériste et des violences de masse commises durant ce conflit, vient l'ethnographie proprement dite de Valérie Robin Azevedo. Menée dans deux villages d'Ayacucho, Occros et Huancapi, celle-ci nous dévoile les "modalités de réélaboration des catégories de "vérité" et de "victime" et la façon dont les acteurs sociaux "bricolent", s'approprient, reformulent voire détournent ces catégories» (p. 125). À Occros, l'autrice assiste à une représentation théâtrale par les habitants du massacre de Ceraocro, "procédé narratif [qui] met la violence à distance et la dépersonnalise» (p. 132) et "acte d'écriture de l'histoire que les acteurs ont choisi de raconter» (p. 136). Elle souligne à quel point ces représentations théâtralisées de la 
guerre distinguent les «bonnes» victimes, celles qui ont subi les exactions du Sentier lumineux, des «mauvaises», celles supposées proches de ce mouvement. L'enjeu est le suivant: "un individu exécuté extrajudiciairement par les forces de l'ordre, mais suspecté d'avoir eu le moindre rapport avec les "subversifs" se voit écarté d'office du Registre unique de victimes (Ruv) et donc empêché de bénéficier des politiques de réparation" (p. 153). Mais ces "mémoires manipulées" n'évitent pas des formes de résistance, des contre-narrations, notamment chez les femmes, épouses, sœurs, filles de victimes des forces armées, en quête également de vérité pour leurs proches disparus. Et puis, il y a les silences qui permettent d' "éviter la réactivation douloureuse de blessures du passé à peine cicatrisées» (p. 161) et les secrets "connus de tous mais dont le contenu doit demeurer caché à ceux qui ne font pas partie du groupe» (p. 162). Ainsi l'autrice note-t-elle une opposition entre la figure du héros et celle de la victime dans les bricolages mémoriels par les populations.

Dans le dernier chapitre de l'ouvrage, Valérie Robin Azevedo analyse avec finesse la façon dont les habitants du village de Huancapi, dont la fondation est attribuée au roi de France Saint Louis, élaborent, à l'occasion de la défense du cèdre trônant sur la place centrale du village - alors vu comme le double de Saint Louis -, "une mémoire collective héroïque et victorieuse qui permet de donner un autre sens à l'expérience douloureuse des deux dernières décennies du $\mathrm{xx}^{\mathrm{e}}$ siècle». Ce qui se joue alors, souligne l'autrice, ce n'est pas tant de savoir si le saint protecteur et miraculeux a véritablement réussi à protéger les villageois des exactions de l'armée occupante, mais plutôt « la constitution d'une mémoire collective positive, dont les individus peuvent se sentir fiers» (p. 214) permettant, dans une lecture des relations de pouvoir chère à James Scott, "une inversion de la situation de domination et d'abus vécus par les villageois» (p. 216).

Cet essai d'anthropologie des mémoires de guerre à partir du cas péruvien qui présente, dans une écriture limpide, une ethnographie richement documentée témoignant d'une grande familiarité avec ce terrain des Andes péruviennes, mais aussi avec la littérature qui lui est dédiée, ouvre de nombreuses pistes de réflexion stimulantes pour d'autres terrains traversés par des problématiques et des enjeux similaires.

Sébastien Boulay 